\title{
Private Investment and the Great Recession
}

\author{
Fernando M. Martin, Senior Economist
}

usiness cycles are mainly about fluctuations in pri-

vate investment: During recessions, private investment contracts proportionally more than output; during expansions, it expands proportionally more. Although private consumption moves in tandem with the business cycle, it exhibits considerably less variation than investment. One reason for these patterns is that households want to maintain, as much as they can, a stable standard of living (food, shelter, clothing, etc.) through booms and busts. Financial instruments such as savings and insurance help them achieve this.

Private investment behaved as usual during the most recent recession. However, inspecting the evolution of its major components reveals some unusual facts that may help us better understand this episode.

The past recession lasted from 2007:Q4 to 2009:Q2. During this period, real private investment per capita fell by 21.1 percent. As of 2015:Q3, it is about 5.7 percent above its pre-recession level. By comparison, real GDP per capita contracted by 5.5 percent during the recession and is now about 2.9 percent above its pre-recession level. The magnitude of the contraction of these variables during the recession was unusually large, which is one reason it was dubbed the "Great Recession."

Unlike other components of private investment, residential investment has not yet recovered and remains well below its pre-recession level.

There are three major components in private investment: nonresidential investment, residential investment, and expenditure on consumer durables. Note that the National Income and Product Accounts (NIPA) considers consumer durables as part of private consumption rather than investment. In many applications, however, economists include them in investment, as consumer durables allow households to produce output themselves that would otherwise be acquired from the marketplace. ${ }^{1}$ The figure shows the three major investment components from 1955:Q1 to 2015:Q3 expressed in 2009 dollars and divided

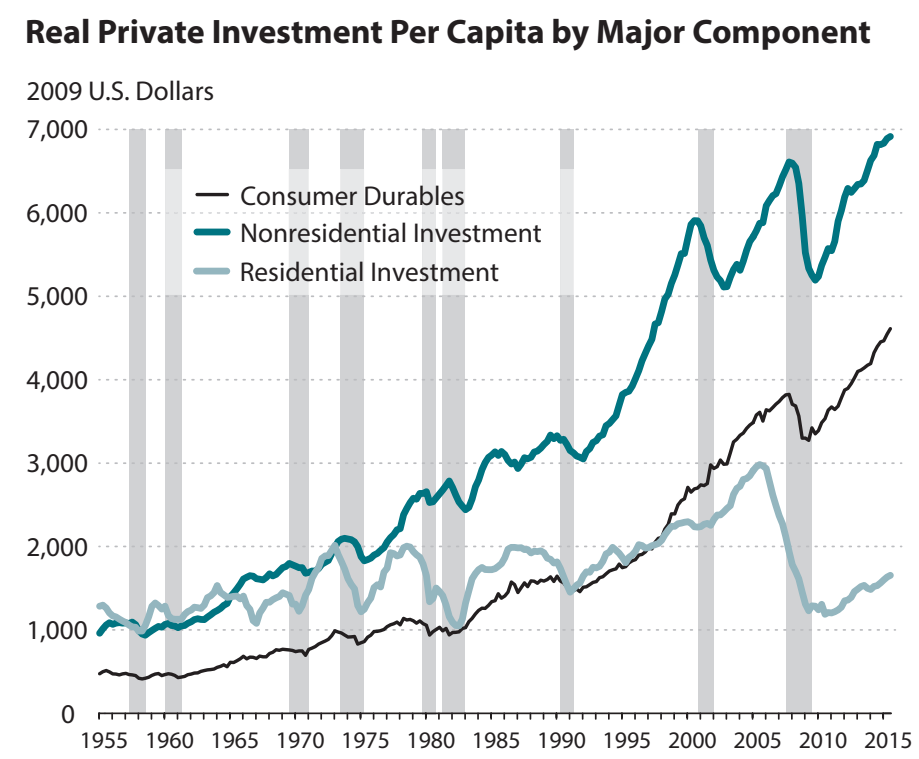

NOTE: The shaded bars indicate recessions as determined by the National Bureau of Economic Research.

SOURCE: Haver Analytics and authors' calculations.

by the total population. The shaded bars in the figure indicate recessions as defined by the National Bureau of Economic Research (NBER). As we can see, all major private investment components contracted significantly during the Great Recession. This is where the similarities end, however, so let us consider each component separately.

Consumer durables are by far the least-volatile component in private investment, which is natural since they provide consumption services. The contraction during the past recession was unusually severe. Since then, expenditures on consumer durables per capita have expanded at a rapid pace. As of 2015:Q3, it is 20.8 percent above its prerecession level. To a large extent, this recovery was fueled by expenditures on recreational goods (e.g., televisions, personal computers, and smartphones).

Nonresidential investment (commercial structures, equipment, and intellectual property) is currently the largest component and its behavior is similar to that of total private investment. Real nonresidential investment per capita contracted by 18.1 percent during the past recession. As of 
2015:Q3, it is 6.1 percent above its pre-recession level. Most of the recovery has been driven by investment in equipment and the ongoing increase in intellectual property products (e.g., software and research and development).

Residential investment followed a different path. Before the recent housing boom, real residential investment per capita exhibited no trend and was quite volatile. Between 1990 and 2005, it rose considerably and then collapsed dramatically. From its peak in 2005:Q3 to the end of the recession in 2009:Q2, real residential investment per capita fell by 58.7 percent. Note that the beginning of the contraction in residential investment predates both the collapse in house prices, which started sometime in 2006, and the subsequent financial crisis of 2007-08. This is not entirely unusual, as residential investment also collapsed well before the start of some previous recessions (e.g., the recessions in the 1970s and 1980s). ${ }^{2}$ Unlike the other two components, residential investment has not yet recovered. As of 2015:Q3, it is 22.0 percent below its pre-recession level and 44.5 percent below its peak.

The differences between residential investment and the other two components are also manifested in prices. Both consumer durables and nonresidential investment have become relatively cheaper over time. Over the past 25 years, the price of consumer durables has decreased by almost 60 percent relative to the average consumer good as measured by the personal consumption expenditures (PCE) price index. Similarly, the cost of nonresidential investment has fallen by 30 percent relative to the PCE price index. Both these declines have been steady. In contrast, the price of residential investment experienced an unprecedented boom from the mid-1990s until 2005 and was followed by a sharp collapse and, more recently, a healthy recovery. Relative to 1995:Q1, this price increased by 29 percent at its peak in 2006:Q4, then dropped to about 11 percent in 2012:Q1, and stands at 23 percent as of 2015:Q3.
Overall, private investment behaved as usual during the past recession, although the severity of this episode also meant an atypically large contraction in investment. Inspecting the major components of investment reveals that the subsequent recovery followed the usual pattern in nonresidential investment and was particularly helped by the expansion in consumer durables expenditures. In contrast, residential investment collapsed well before the start of the Great Recession and has not yet recovered. In this regard, Boldrin et al. (2013) argue that the contraction of the construction sector contributed significantly to the overall performance of the U.S. economy during the Great Recession.

\section{Notes}

\begin{abstract}
1 Some examples of how consumer durables lead to "household production": (i) a car allows the owner to commute instead of using public transportation; (ii) a washer and dryer allow the owner to wash and dry clothes instead of taking them to the dry cleaners; (iii) kitchen appliances and utensils allow the owner to cook meals instead of going to a restaurant; and (iv) a home theater system allows the owner to watch movies at home instead of going to the theater.

2 For more about the relationship between housing and the business cycle, see Leamer (2007).
\end{abstract}

\section{References}

Boldrin, Michele; Garriga, Carlos; Peralta-Alva, Adrian and Sánchez, Juan M. "Reconstructing the Great Recession." Working Paper No. 2013-006B, Federal Reserve Bank of St. Louis, February 2013, revised June 2013; https://research.stlouisfed.org/wp/more/2013-006.

Leamer, Edward E. "Housing IS the Business Cycle." NBER Working Paper No. 13428, National Bureau of Economic Research, September 2007; http://www.nber.org/papers/w13428. 